\title{
Corrigendum: Large-Scale Neuromorphic Spiking Array Processors: A Quest to Mimic the Brain
}

\section{OPEN ACCESS}

\section{Approved by: \\ Frontiers in Neuroscience Editorial Office,}

Frontiers Media SA, Switzerland

${ }^{*}$ Correspondence: Chetan Singh Thakur csthakur@iisc.ac.in

Specialty section: This article was submitted to Neuromorphic Engineering,

a section of the journal

Frontiers in Neuroscience

Received: 07 December 2018 Accepted: 10 December 2018

Published: 07 January 2019

Citation:

Thakur CS, Molin JL, Cauwenberghs $\mathrm{G}$, Indiveri $\mathrm{G}$, Kumar K, Qiao N, Schemmel J, Wang R, Chicca E, Hasler JO, Seo J,

Yu S, Cao Y, van Schaik $A$ and

Etienne-Cummings $R$ (2019)

Corrigendum: Large-Scale

Neuromorphic Spiking Array

Processors: A Quest to Mimic the

Brain. Front. Neurosci. 12:991

doi: 10.3389/fnins.2018.00991

\section{Chetan Singh Thakur ${ }^{1 *}$, Jamal Lottier Molin ${ }^{2}$, Gert Cauwenberghs ${ }^{3}$, Giacomo Indiveri ${ }^{4}$, Kundan Kumar ${ }^{1}$, Ning Qiao ${ }^{4}$, Johannes Schemmel ${ }^{5}$, Runchun Wang ${ }^{6}$, Elisabetta Chicca ${ }^{7}$, Jennifer Olson Hasler ${ }^{8}$, Jae-sun $\mathrm{Seo}^{9}$, Shimeng $\mathrm{Yu}^{9}$, Yu Cao ${ }^{9}$, André van Schaik ${ }^{6}$ and Ralph Etienne-Cummings ${ }^{2}$}

${ }^{1}$ Department of Electronic Systems Engineering, Indian Institute of Science, Bangalore, India, ${ }^{2}$ Department of Electrical and Computer Engineering, Johns Hopkins University, Baltimore, MD, United States, ${ }^{3}$ Department of Bioengineering and Institute for Neural Computation, University of California, San Diego, La Jolla, CA, United States, ${ }^{4}$ Institute of Neuroinformatics, University of Zurich and ETH Zurich, Zurich, Switzerland, ${ }^{5}$ Kirchhoff Institute for Physics, University of Heidelberg, Heidelberg, Germany, ${ }^{6}$ The MARCS Institute, Western Sydney University, Kingswood, NSW, Australia, ${ }^{7}$ Cognitive Interaction Technology - Center of Excellence, Bielefeld University, Bielefeld, Germany, ${ }^{8}$ School of Electrical and Computer Engineering, Georgia Institute of Technology, Atlanta, GA, United States, ${ }^{9}$ School of Electrical, Computer and Engineering, Arizona State University, Tempe, AZ, United States

Keywords: neuromorphic engineering, large-scale systems, brain-inspired computing, analog sub-threshold, spiking neural emulator

\section{A Corrigendum on}

Large-Scale Neuromorphic Spiking Array Processors: A Quest to Mimic the Brain by Thakur, C. S., Molin, J. L., Cauwenberghs, G., Indiveri, G., Kumar, K., Qiao, N., et al. (2018). Front. Neurosci. 12:891. doi: 10.3389/fnins.2018.00891

In the original article, there were mistakes in Table 5, Comparison of event-based neural processors, as published. The area per neuron for the transistor channel was incorrectly provided as " $4 \mathrm{~cm}^{2}$ " and should be "-" (empty). The synaptic plasticity for true North was incorrectly provided as "STDP" and should be "No Plasticity." The area per neuron for Loihi was incorrectly provided as " $0.4 \mathrm{~mm}^{2}$ " and should be " $0.4 \mathrm{~mm}^{2 *}$." The corrected Table 5, Comparison of event-based neural processors, appears below.

The authors apologize for these errors and state that the do not change the scientific conclusions of the article in any way. The original article has been updated.

Copyright ( 2019 Thakur, Molin, Cauwenberghs, Indiveri, Kumar, Qiao, Schemmel,Wang, Chicca, Hasler, Seo, Yu, Cao, van Schaik and Etienne-Cummings. This is an open-access article distributed under the terms of the Creative Commons Attribution License (CC BY). The use, distribution or reproduction in other forums is permitted, provided the original author(s) and the copyright owner(s) are credited and that the original publication in this journal is cited, in accordance with accepted academic practice. No use, distribution or reproduction is permitted which does not comply with these terms. 
TABLE 5 | Comparison of event-based neural processors.

\begin{tabular}{|c|c|c|c|c|c|c|c|c|}
\hline Chip name & Technology & $\begin{array}{l}\text { Process } \\
(\mathrm{nm})\end{array}$ & Neurons type & \#Neurons & \#Synapse & $\begin{array}{l}\text { Area per } \\
\text { neuron }\end{array}$ & $\begin{array}{l}\text { \#Energy per } \\
\text { event }\end{array}$ & Synaptic plasticity \\
\hline MNIFAT & Mixed Signal & 500 & LIF/M-N & 6,120 & - & $1,495 \mu \mathrm{m}^{2}$ & $360 \mathrm{pJ}$ & Programmable \\
\hline Dynap-SEL & Mixed Signal & 28 & I\&F & 1,088 & 78,080 & $20 \mu \mathrm{m}^{2}$ & $2.8 \mathrm{pJ}$ & STDP \\
\hline BrainScaleS & Mixed Signal & 180 & AdEx IF & 512 & $100 \mathrm{~K}$ & $1,500 \mu \mathrm{m}^{2}$ & 100pJ & $\begin{array}{l}\text { Hebbian learning, } \\
\text { STDP }\end{array}$ \\
\hline $\begin{array}{l}\text { Transistor- } \\
\text { Channel }\end{array}$ & Analog & 350 & $\begin{array}{l}\text { Floating Gate } \\
\text { MOSFET }\end{array}$ & 100 & 30,000 & - & $10 \mathrm{pJ}$ & STDP \\
\hline Neurogrid & Mixed signal & 180 & Adaptive Quad IF & $65 \mathrm{~K}$ & $100 \mathrm{M}$ & $1,800 \mu \mathrm{m}^{2}$ & $31.2 \mathrm{pJ}$ & No Plasticity \\
\hline
\end{tabular}

${ }^{*}$ Neurosynaptic core area with each core implements 1,024 neural units. 